\title{
Effective Dynamic Pricing for E-Commerce Businesses by Estimating Customers Behavior Using Data-Mining
}

\author{
Mark Malcolm Furtado ${ }^{1}$, Sneha Leleat Gonsalves ${ }^{2}$ \\ ${ }^{1,2}$ St. Francis Institute of Technology, Department of Computer Engineering, Mumbai, India
}

\begin{abstract}
The success of any e-commerce website of business lies in how well it is able to balance the needs and demands of its customers as well as how efficient it is in generating enough profit to keep the business running. Alongside, competition plays a key factor in determining how it is able to maintain relations with its customers. Considering every user's shopping perspective isn 't same, as well as the price point every user is comfortable with varies to a certain extend according to his/hers financial condition. Taking in account these factors and also maintaining balance between profit and customer relation poses a challenge. In the proposed solution, we provide a method to dynamically set up the price of every product which is achieved by analyzing user's behavior from his shopping trend and at the same time, making sure maximum profit can be achieved.
\end{abstract}

Keywords: Data Mining, Dynamic Pricing Strategy, E-Commerce, Consumer Behavior Analysis

\section{Introduction}

The Web is one of the most revolutionary technologies that have transformed the business environment, which in turn accelerates the shift of power towards the consumer, leading to essential changes in the way companies relate to their customers and the pricing strategy used. Throughout the globe online buying has grown exponentially, More than $85 \%$ of world's online population has ordered goods over the internet during the recent year [1].

As the market competition has been increasing immensely, retailers are now shifting their focus to dynamic pricing strategy to improve their revenue. However, the behavior of consumer has a significant impact on revenue of retailers, drafting a dynamic pricing strategy that is valid and effective, considers every individual customers behavior and display's prices accordingly acts as an influential element to improve the retailer's profit.

Su proposes that the heterogeneous behavior of the consumer "valuation" and "degree of patience" to buy products can be considered to decide the product prices [2]. Minho Cho and team focused on an analytical approach which determines "strategic consumer delay to buy a product" which gives a simple and effective solution to decide prices of products dynamically [3]. Yossi and Amit, their research draws a model based on "behavior of the consumer to the prices set by the retailer" which help the seller to set prices, discounts on products and stock warehouses with required amount of products [4]. Compared to the above researches, our proposed model focuses on not dividing the consumers into two categories that is strategic and myopic, rather evaluate them based on behavioral score, on a probable scale of 0.01 to 1. As per the individual score of consumer they are presented with the most relevant price which suits, his or hers behavior. This pricing strategy sets prices irrespective of circumstances which benefit both the retailer and the consumer.
The paper is organized as follow: Section 2 elaborates all the system data entry parameters needed by various modules. Detailed working of various modules is been mentioned in Section 3. We discuss in Section 4, example that clears the dynamic pricing strategy proposed by us.

\section{System Data Entry}

This section introduces various parameters needed to be entered or updated by the retailer. The system consists of modules which work in co-relation to each other to provide the most optimal results.

The system requires calculation of certain parameters for efficient working. These parameters are calculated as per information obtained from the data warehouse.

\subsection{Cost Price (CP)}

This is the price the seller pays to buy or manufacture a particular product. This needs to be entered by the user while adding a particular product and the selling price of that product determined by the system will always be greater than $\mathrm{CP}$. The $\mathrm{CP}$ once entered by the seller will not be altered by the system unless the seller prompts the system to.

\subsection{Maximum Selling Price (MSP)}

This is the maximum price at which the seller wants to sell a particular item. This needs to be entered by the user. The MSP will remain same until during daily/monthly data mining it is observed that in the coming days/months, the sales of a particular product are subjected to increase. The MSP will however never decrease below the price entered initially by the seller.

\subsection{Minimum Profit Factor (MPF)}

MPF is a variable which the seller sets up for a particular 


\section{International Journal of Science and Research (IJSR) \\ ISSN (Online): 2319-7064}

Index Copernicus Value (2015): 78.96 | Impact Factor (2015): 6.391

product/category to make sure that the selling price will always be greater than a certain price. For efficient working of the system it is advised to keep it in the range of 0.1 to 0.5 . MPF is used to determine the minimum selling price (MinSP) of the product in the following way:

$$
\operatorname{MinSP}=C P+[(M S P-C P) \times M P F]
$$

Hence we can see the MPF multiplied by 100 is the percentage minimum profit a seller wishes to acquire from the difference between MSP and CP.

\subsection{Discount}

The retailer can provide discount on any or every product in the system. This will ensure that in cases of lower demand for a particular product or in scenarios where the retailer wishes to empty his stockpile of products, reduced prices can be made available to the user. The retailer can initiate a Discount (D) in percentage on any product at any time, even while adding products. It is recommended for the efficient working of the system that no discount be availed during initial stage when the product is added, as the User Behavioral Score (UBS) which is explained in 3.1 is calculated accurately.

The discount is calculated on the CP and the value of MSP is reduced. For the purpose of avoiding accidental excessive discount and incurring loss, the system will issue a warning, if the discounted price is below the SP. Following is the calculation when the retailer mentions a percentage discount of $\mathrm{D}$ percent:

$$
\begin{aligned}
& \operatorname{MSP}(\text { new })=M S P-\left(\frac{D}{100} \times C P\right) \\
& \text { if }(M S P(\text { new })<C P) \\
& C P=M S P(\text { new }) \\
& M S P=M S P(\text { new })
\end{aligned}
$$

else

$$
M S P=M S P(n e w)
$$

If MSP (new) is greater than or equal to CP, the MSP is updated to $\mathrm{MSP}($ new).

If the MSP (new) is less than SP, it means the retailer will incur loss if this discount is applied. The retailer is prompted before applying this discount. Only on accepting the prompt, the system makes the following changes:

\section{Working of the System}

Once the CP, MSP, MPF have been set while adding products, the system works as multiple modules. Every module works in correlation with each other to ensure that the user is presented with the most optimal price according to his shopping tendency

The overlay of the process flow is explained in Figure 1

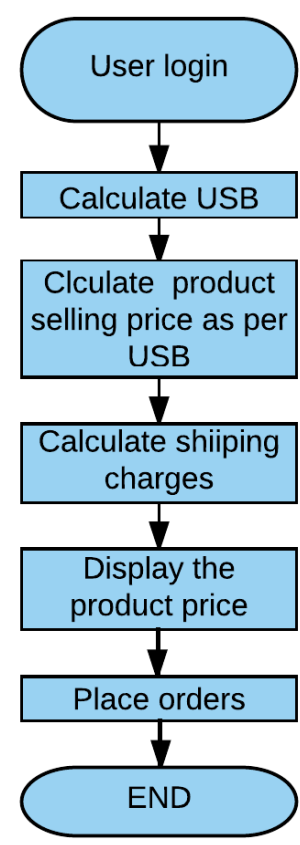

Figure 1: The overview of entire flow of dynamic stragergy proposed.

Sections below explain the process involved.

\subsection{Calculating User Behavior Score (UBS)}

How a user browses through products and how many products he choose to buy in the past, explains a lot about how likely the user is going to spend. According to the shopping patterns of a user, each user is given a UBS score, which determines how likely he/she is to spend more or less. The UBS will only be in the range of 0 to 1 . Initially when the user registers, the UBS is set to the following:

$$
U B S=\frac{M P F+1}{2}
$$

The above equation will provide average between the MPF and highest value of UBS, and is only valid for first time registering users.

For returning registered users, every time a user logins, UBS is calculated. A data warehouse maintains the entire shopping history of every user, and specifically mentions weather the product was bought when discount was applied on it or when no discount was levied on the same. This information is extracted from the data warehouse during UBS calculation. The ratio between the number of non-discounted products and the discounted products gives us the ratio as to how likely a user is to buying non-discounted products. This value is only calculated once per session in the following way:

$$
U B S(n e w)=\left[\frac{\sum n d}{\sum d}\right]
$$

$\sum$ nd : Sum of all non-discounted products bought by user. $\sum \mathrm{d}$ : Sum of all discounted products bought by user.

Thus the ratio between the non-discounted as well as the discounted products bought by the user so far is used in calculating the new UBS. Also a consideration should be

Volume 6 Issue 7, July 2017 www.ijsr.net 


\section{International Journal of Science and Research (IJSR) \\ ISSN (Online): 2319-7064 \\ Index Copernicus Value (2015): 78.96 | Impact Factor (2015): 6.391}

given to divide by zero scenario, hence a nominal value of 1 will be given to $\sum \mathrm{d}$ if its value is 0 .

$$
\begin{aligned}
& \text { if }(U B S(\text { new })>1) \\
& U B S=1 \\
& \text { if }(U B S(\text { new })<M P F) \\
& U B S=U B S(\text { old }) \\
& \text { else } \\
& \quad U B S=U B S(\text { new })
\end{aligned}
$$

If the newly calculated value is greater than 1 , the UBS is set to 1 . If the new value of UBS is less than the value of MPF, the UBS is unchanged and is kept the same as it was before calculating the new UBS. These conditions make sure that the price calculated in the next stage is compatible with the MinSP and MSP.

Also keeping the UBS same as previous when UBS is less than MPF instead of assigning it value of MPF will reduce the chances of UBS directly getting reduced to minimum if the user keeps buying discounted products in much higher proportion. Detailed flow is provided in fig. 2.

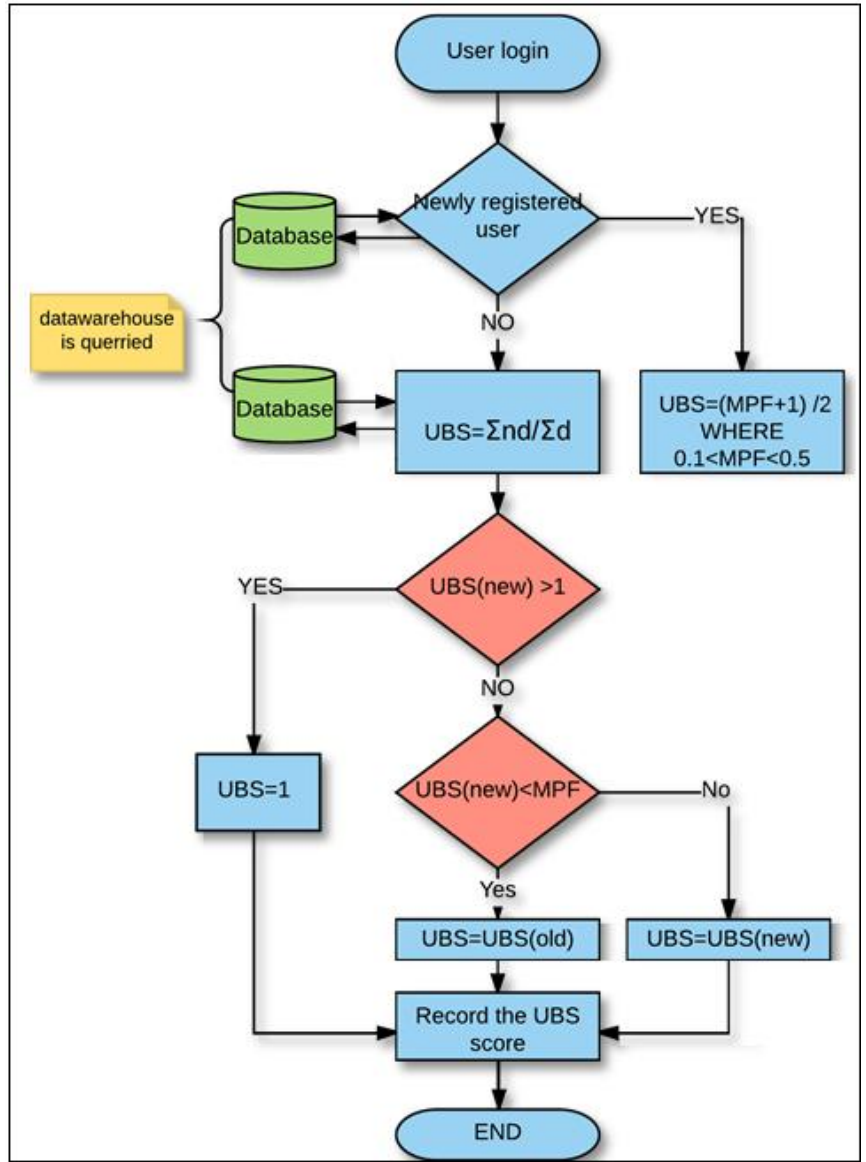

Figure 2: UBS calculations

\subsection{Calculate Price of the product}

Once the User Behavior Score (UBS) is calculated, the price of each product as the user searches for it or browses for it is calculated dynamically. Based on a particular users UBS a suitable price is shown to him/or considering the products Cost Price (CP), Maximum Selling Price (MSP) and Minimum Selling Price (MinSP). This price of a particular product is calculated as follows:

$$
\text { Price }=C P+[(M S P-C P) \times U B S]
$$

If the Price is less than MinSP, the price will be set to MinSP, if the price is greater than MSP, the Price is given value of MSP. Hence it is made sure that the price does not exceed the minimum requirement of the price (MinSP) based on Minimum Profit Factor (MPF), as well as the maximum price (MPF) specified for that product. Detailed price calculation is explained in Figure 3

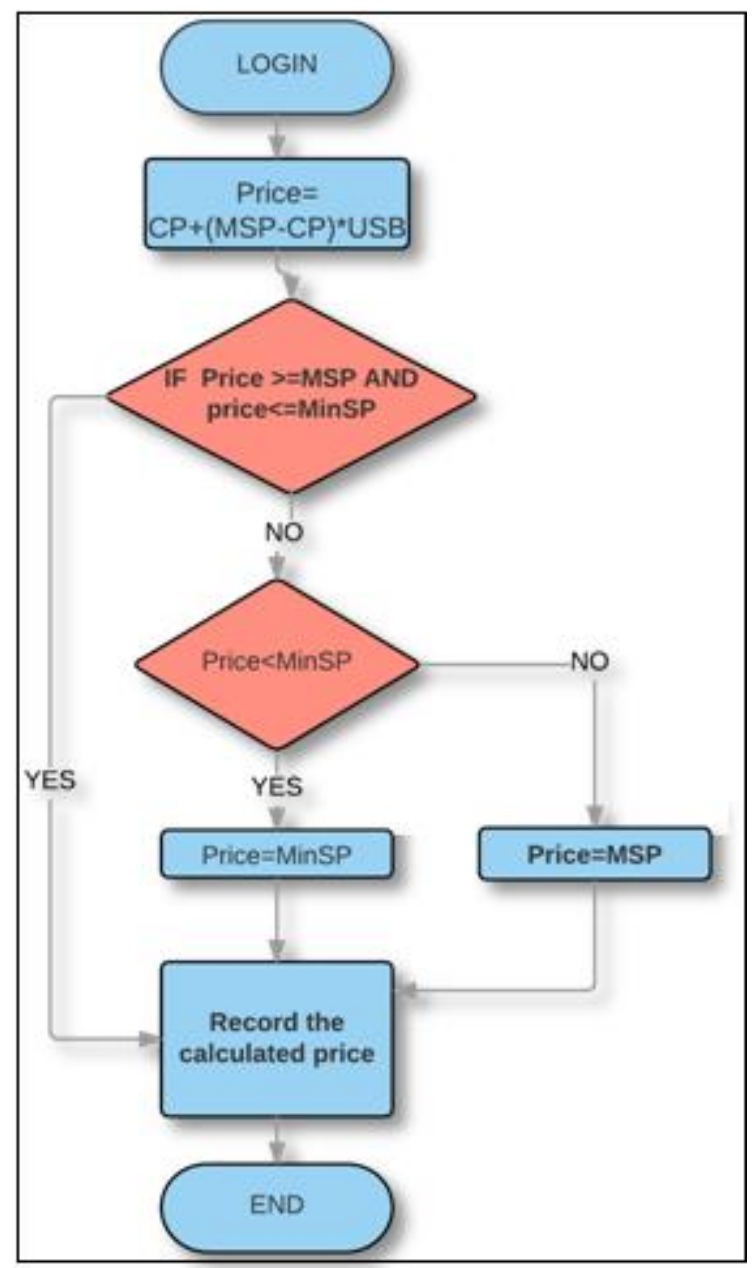

Figure 3: Flowchart for price calculation of a product

\subsection{Addition of Other Charges}

Shipping charges simply mean amount charged for transportation of products. Taxes on a product are the fees charged by the government, As per studies the shipping charges and all implicit taxes when added to the products isn't appealing to the customers and is the number one driving factor for cart abandonment the graph below supports the study [5]. Majority of E-commerce companies partner with various courier service providers to handle their shipping. So it is the courier service providers who decide the shipping charges.

\section{Volume 6 Issue 7, July 2017 www.ijsr.net}




\section{International Journal of Science and Research (IJSR) \\ ISSN (Online): 2319-7064}

Index Copernicus Value (2015): 78.96 | Impact Factor (2015): 6.391

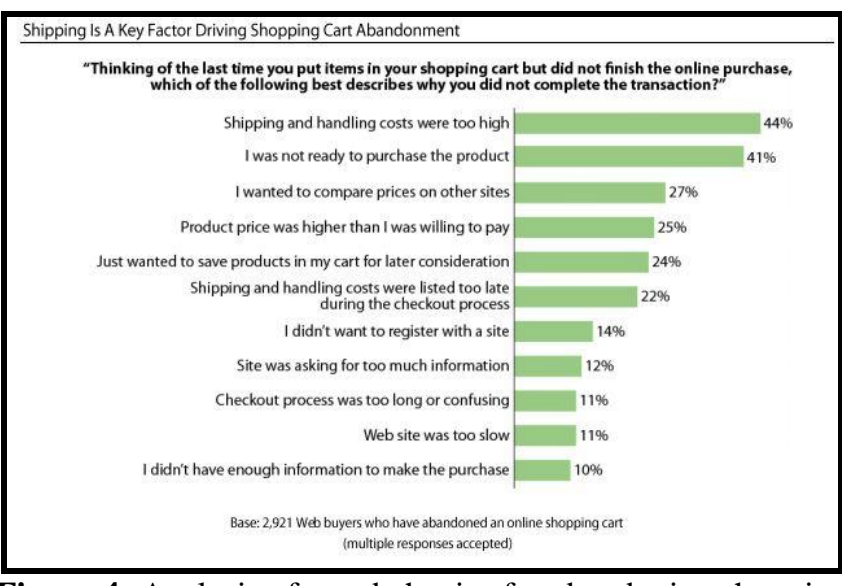

Figure 4: Analysis of user behavior for abandoning shopping carts

As per our propose idea the shipping charges and taxes which is the major reason for cart abandonment will be added to the product price displayed to the user, it will vary according to the pincode of the consumer which he enters in his address.

This shipping charges for areas will be negotiated prior with the retailers by the courier service providers, thereby avoiding such impulsive nature of consumers.

\subsection{Determining new Maximum Selling Price as per Estimated Seasonal Sales}

Demand for every product increases during certain time frames. Like for example, during the winter season, sales of warm clothing increase dramatically hence, this increased demand can be in turn be used to increase profit. The system consists of a module which can be configured to run automatically on first day of every month. The following equation states how the prices are increased accordingly:

$$
S F=\frac{\left(\sum c m s\right) \times 12}{\sum t s}
$$

SF : Sales Factor

$\sum \mathrm{cms}:$ Sales of the product same month last year

$\sum$ ts : Sales of the product in the entire last year

A product's total sales are derived from the past one year sales database, along with it the corresponding sales of the current month last year. From those two values, a ratio is calculated (SF) to check if the sale can be predicted to increase.

$$
\begin{aligned}
& \text { if }(S F<1) \\
& \quad M S P(\text { new })=M S P \\
& \text { if }(S F>1.8) \\
& \quad M S P(\text { new })=C P+[(M S P-C P) \times 1.8] \\
& \text { else } \\
& \quad M S P(\text { new })=C P+[(M S P-C P) \times S F]
\end{aligned}
$$

$M S P=M S P(n e w)$
If the factor is less than 1, the MSP is set same as that specified by the retailer. If the factor is greater than 1 , it states sales were above the average for that month last year, hence the MSP is increased by that factor. To prevent increase of MSP way too high, SF is given a highest cap of 1.8. This cap is implemented in (10) shown above. However, if necessary, this cap can also be increased or decreased based on the retailer's requirements.

\section{Working of the System with Example}

To explain the proper working of the system, let's consider a scenario involving the sale of a product A. The retailer while adding the product considered the following parameters:

CP : $\$ 100$

MSP: $\$ 140$

MPF: 0.25

$\mathrm{D}: 0 \%$

A tax of 5\% and a shipping charge of $\$ 5$ will also be considered. As mentioned in (1) the Minimum Selling Price (MinSP) is calculated which is $\$ 110$. As Discount (D) is $0 \%$, the value of MSP after (2), (3) will be the same that is $\$ 110$.

\subsection{Price for a new customer}

In this case, we assume the customer $\mathrm{C} 1$ who just registered, and hence has no shopping history. As a result, the UBS will be calculated based on (4). Therefore the UBS for customer $\mathrm{C} 1$ will be 0.625 .

The price for product A has to be calculated for customer C1 based on his UBS. Section 3.2 explains how the price is calculated. The price for product A according to (8) will be $\$ 125$. This is the price calculated for customer C1. Before displaying it to the customer, tax and shipping charges have to be added. On calculating tax and shipping charges according to values mentioned in this scenario. The final price after adding tax and shipping charges will be $\$ 136.25$. This is the final price which will be displayed to the customer $\mathrm{C} 1$ for product $\mathrm{A}$.

\subsection{Price for existing customer who buys more discounted products}

Consider a customer $\mathrm{C} 2$ who has been regularly shopping and tends to buy discounted products whenever possible. Hence for such customer, the UBS will be lower, and to make such customer more likely to buy the product, the price will be less for him compared to other customers. And at the same time it is also made sure that the retailer gets adequate profit and doesn't suffer loss.

The customer $\mathrm{C} 2$ on fetching his previous sales data from data warehouse has bought 70 discounted products and 30 non discounted products so far. Considering the same product $\mathrm{A}$ with the same parameters mentioned above in section 4, we can find the UBS for him using (5), (6) and (7). Hence the UBS for customer $\mathrm{C} 2$ will be 1 . Using this value of UBS, in (8) the Price for product A will be calculated, which will be $\$ 117.12$. Before displaying it to the customer, tax and shipping charges are added to it. Hence the final

\section{Volume 6 Issue 7, July 2017 www.ijsr.net}




\section{International Journal of Science and Research (IJSR) \\ ISSN (Online): 2319-7064 \\ Index Copernicus Value (2015): 78.96 Impact Factor (2015): 6.391}

price will be $\$ 127.98$. This is the final price that will be displayed to the customer $\mathrm{C} 2$ for product $\mathrm{A}$

\subsection{Price for existing customer who doesn't emphasize much on discounts.}

Consider a customer C3 who shops regularly, and doesn't pay much attention to if the products are discounted or not. For such customer, the UBS score will be higher compared to customers who buy more discounted products.

The customer $\mathrm{C} 3$, on fetching his sales history from the data warehouse has bought 10 discounted products and 40 non discounted products so far. For product A with the same parameters mentioned above in section 4 we can find the UBS for C3 using (5), (6) and (7). Hence the UBS for customer C3 will be 0.428 . Using this value of UBS, in (8) the Price will be calculated which will be $\$ 140$. Before displaying it to the customer, tax and shipping charges are added to it. Hence the final price will be $\$ 152$. This is the final price that will be displayed to the customer $\mathrm{C} 3$ for product $\mathrm{A}$

\subsection{Seasonal Price Change}

Demand of certain products increase during certain intervals, hence to take the most advantage of such case, the Price Change is executed every first day of the month. Consider the same product A. Assuming this is being done on the $1^{\text {st }}$ of January 2017, on fetching data from data warehouse regarding the sales of product $\mathrm{A}$, we observe the total sales of product A in 2016 were 24000 units and the sales of product A in January 2016 were 3000 units.

Considering the above results, SF is calculated as shown in (9). The Sales Factor (SF) will be 1.5. This roughly gives an idea the sales in month of January were up by $50 \%$ compared to the overall sales. Hence, from this SF, the new MSP will be calculated based on (10), which in this scenario will be $\$ 160$. Hence after the new value of MSP has been calculated, all equations which rely upon the value of MSP, consider this new value. And accordingly the price for product A will increase for every customer.

\subsection{Discount on Products}

To reduce the stockpile of products the retailer may issue discount. Consider product A mentioned above in section 4 . The retailer decides to issue a $10 \%$ discount on the product. Hence as mentioned in (2), (3), the new MSP will be $\$ 130$.

Every such discounted product that the customer has bought, their sum is considered as $\sum \mathrm{d}$ in (5), while remaining products on which no discount has been applied by the retailer, their sum is considered as $\sum$ nd.

\section{References}

[1] U.Cheema, M.Rizwan, R.Jalal, F.Durrani, N.Sohail: "Trend of online shopping in $21^{\text {st }}$ Century: Impact of enjoyment In TAM model". Asian Journal of Empirical Research 3(2):131-141. 131.

[2] X. Su, F .Zhang. "Strategic customer behavior, commitment and supply chain performance," Management Science, vol. 54, pp.1759-1773, 2008.

[3] Minho Cho, Ming Fan, Yong-Pin Zhou:"Strategic Consumer Response to Dynamic Pricing of Perishable Products".[Available:http://faculty.washington.edu/yongp in/StrategicConsumer_BookChapter.pdf].

[4] Aviv.Y, Pazgal,A."Optimal pricing of seasonal products in the presence of forward-looking consumers," Manufacturing \& Service Operations Management, vol. 10, pp. 339-359, 2008.

[5] "Smarter strategies for free shipping" by A Forrester consulting thought Leadership paper Commissioned By UPS.[Available:https://www.ups.com/media/en/Smarter_ Strategies_for_Free_Shipping.pdf]

\section{Author Profile}

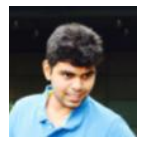

Mark Malcolm Furtado received the B.E. in Computer Engineering from St. Francis Institute of Technology in 2016. During his course of engineering he mainly emphasized on Data Mining, Information Management, ERP and Web Technologies. Alongside he also shares enthusiasm for programming and strives to find simpler solutions to complex problems using technology. He believes "The harder I work, the luckier I seem to be".

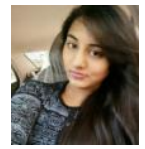

Sneha Leleat Gonsalves compeleted B.E. in Computer Engineering from St. Francis Institute of Technology in 2017. She has been keen towards areas that focused on ERP, Data-Mining and Information Management, and has constantly been putting efforts to get better at those areas during all her course because she believes "You get what you work for, not what you wish for". 